\title{
Steep HIV prevalence declines among young people in selected Zambian communities: population-based observations ( I 995-2003)

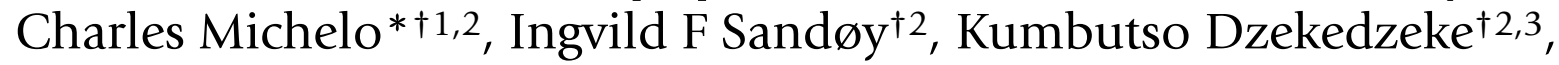 Seter Siziya ${ }^{\dagger 1}$ and Knut Fylkesnes ${ }^{\dagger 2}$
}

Address: ${ }^{1}$ Department of Community Medicine, School of Medicine, University of Zambia, Lusaka, Zambia, ${ }^{2}$ Centre for International Health, University of Bergen, 5021 Bergen, Norway and ${ }^{3}$ Central Statistical Office, Lusaka, Zambia

Email: Charles Michelo* - cmi047@student.uib.no; Ingvild F Sandøy - Ingvild.Sandoy@cih.uib.no; Kumbutso Dzekedzeke - Kumbutso.Dzekedzeke@student.uib.no; Seter Siziya - ssiziya@yahoo.com; Knut Fylkesnes - Knut.Fylkesnes@cih.uib.no

* Corresponding author †Equal contributors

Published: 10 November 2006

BMC Public Health 2006, 6:279 doi:10.1 I86/147|-2458-6-279
Received: 27 July 2006

Accepted: 10 November 2006

This article is available from: http://www.biomedcentral.com/I47I-2458/6/279

(C) 2006 Michelo et al; licensee BioMed Central Ltd.

This is an Open Access article distributed under the terms of the Creative Commons Attribution License (http://creativecommons.org/licenses/by/2.0), which permits unrestricted use, distribution, and reproduction in any medium, provided the original work is properly cited.

\begin{abstract}
Background: Understanding the epidemiological HIV context is critical in building effective setting-specific preventive strategies. We examined HIV prevalence patterns in selected communities of men and women aged 15-59 years in Zambia.

Methods: Population-based HIV surveys in $1995(n=3158), 1999(n=373$ I) and $2003(n=475$ I) were conducted in selected communities using probability proportional to size stratified randomcluster sampling. Multivariate logistic regression and trend analyses were stratified by residence, sex and age group. Absence, $<30 \%$ in men and $<15 \%$ in women in all rounds, was the most important cause of non-response. Saliva was used for HIV testing, and refusal was $<10 \%$.
\end{abstract}

Results: Among rural groups aged I5-24 years, prevalence declined by $59.2 \%$ (I5.7\% to 6.4\%, $\mathrm{P}<$ $0.001)$ in females and by $44.6 \%(5.6 \%$ to $3.1 \%, P<0.00 I)$ in males. In age-group $15-49$ years, declines were less than $25 \%$. In the urban groups aged $15-24$, prevalence declined by $47 \%$ ( $23.4 \%$ to $12.4 \%, P<0.00 \mathrm{I})$ among females and $57.3 \%(7.5 \%$ to $3.2 \%, \mathrm{P}=0.00 \mathrm{I})$ among males but were $32 \%$ and $27 \%$ in men and women aged 15-49, respectively. Higher educated young people in 2003 had lower odds of infection than in 1995 in both urban [men: AOR $0.29(95 \% \mathrm{Cl} 0.14-0.60)$; women: AOR $0.38(95 \% \mathrm{Cl} 0.19-0.79)$ ] and rural groups [men: AOR $0.16(95 \% \mathrm{Cl} 0.1 \mathrm{I}-0.25)$, women: AOR $0.10(95 \% \mathrm{Cl} 0.0 \mathrm{I}-7.34)]$. Although higher mobility was associated with increased likelihood of infection in men overall, AOR, I.7I $(95 \% \mathrm{Cl} 1.34-2.19)$, prevalence declined in mobile groups also (OR $0.5295 \% \mathrm{Cl} 0.3 \mathrm{I}-0.88$ ). In parallel, urban young people with $\geq$ I I school years were more likely to use condoms during the last casual sex (OR $2.9695 \% \mathrm{Cl}$ I.93-4.52) and report less number of casual sexual partners (AOR $0.3395 \% \mathrm{Cl} 0.19-0.56$ ) in the last twelve months than lower educated groups.

Conclusion: Steep HIV prevalence declines in young people, suggesting continuing declining incidence, were masked by modest overall declines. The concentration of declines in higher educated groups suggests a plausible association with behavioural change. 


\section{Background}

HIV prevalence patterns and trends derived from available country data in sub-Saharan Africa, has been useful in improving the understanding of national estimates as well as proving strong basis for strengthening and or adjusting interventions [1-3]. The predominant epidemiological surveillance system for estimating HIV prevalence trends at country level in sub-Saharan Africa is antenatal clinic (ANC) based [4-7]. Despite this widespread use of ANCbased trends, validity and accuracy concerns as well as changing HIV dynamics in general populations as the epidemic matures, continue to pause interpretation challenges when these estimates are extrapolated to the general population[6,8-10]. However, population-based data on trends in HIV prevalence and related risk factors are still limited because only a few serial surveys have been conducted[2,10-13]. Furthermore, potential biases are also likely to hamper validity and reliability of population-based HIV surveys[14].

Zambia has established a comprehensive system for following the dynamics of the HIV epidemic which includes ANC-based surveillance and population-based surveys measuring infection and risk concomitantly over time $[5,10,15]$. In addition, a nationally representative population-based HIV prevalence survey has been conducted[16]. Evidence from ANC-based data shows declining prevalence trend in young pregnant women, a pattern that is masking differential geographical trends overall $[5,17]$. However, when population-based trends are compared with ANC-based estimates from the same community, declines are steeper in young people in the general population[10]. Furthermore, population-based data shows a significant shift towards reduced risk differentials amongst higher educated groups $[5,10,11,15,18]$. Therefore, there is need to understand and explain the existing HIV prevalence patterns in order to build an information base for prevention as well as monitoring and evaluation.

We investigated population-based HIV prevalence trends in the general population in Zambia from 1995 to 2003

\section{Methods \\ Population and sampling procedures}

The data is from three serial population-based HIV surveys conducted in $1995(\mathrm{n}=3158), 1998(\mathrm{n}=3757)$ and $2003(\mathrm{n}=4775)$ in selected rural (Kapiri Mposhi) and urban (Chelstone, Lusaka) areas in Zambia using stratified random-cluster sampling method. The detailed methods of the surveys conducted in 1995-6 and 1998-9 have been reported elsewhere[10,17]. The sampling frame consisted of 24 Standard Enumeration Areas (SEAs) with 2786 households in Chelstone and 26 SEAs (5225 households) in Kapiri Mposhi. The SEA defined the primary sampling unit (cluster) of the study. Using probability proportional to size, 10 SEAs in Chelstone and 5 SEAs in rural Kapiri Mposhi were initially (1995) selected for the baseline survey. The numbers of SEAs in rural Kapiri Mposhi were increased to 10 in 1999 and 2003. All household members aged 15-59 in the selected clusters were listed and invited to participate in the study.

\section{Data Collection}

In the sampled clusters (SEAs), a personal structured interview was carried out with all eligible and willing household members in order to collect information on sociodemographic and behavioural characteristics. Information on people who were not found in the subsequent survey was collected. At the end of the interview the participants were asked to provide a saliva sample for HIV testing.

\section{Laboratory Investigation}

A standard algorithm that uses two-test strategy was employed in all the survey rounds. In the 1995 survey, all saliva samples were tested using Gacelisa HIV 1 \& 2 (Welcome Diagnostics, Dartford, Kent, U.K.) and in addition, 450 randomly selected samples were tested using Bionor HIV-1\&2 (BIONOR AS) magnetic particle assay following modifications for saliva. The two test kits showed a $99.8 \%$ agreement. The accuracy of Gacelisa was validated based on paired saliva and serum samples collected from 494 antenatal clinic attendees, and both sensitivity and specificity were $100 \%[19]$. In addition, all respondents who wanted to know their results had their serum tested also in addition to saliva in accordance with the requirement in this country. This was useful for both as a validation strategy as well as quality assurance strategy $[11,19]$. In cases of discordance, the test result from serum was considered final. In the 1999 and 2003 follow-up surveys, samples were tested using Bionor HIV 1 \& 2 and Gacelisa was only used in prescribed circumstances as a second test. In all the survey rounds, $10 \%$ of negative and $10 \%$ of positive samples were periodically sampled and re-tested for exactness with initial results and a different and senior person from a different section of the reference laboratory did this. Furthermore, in 2003, a second saliva test was done all the saliva specimens that tested positive but had no corresponding serum results, and were only considered positive if this second test was positive also. In case of discordance, a third test was done to decide the result. Once collected, these specimens were stored in a central place and then transported once a week for testing at a national reference laboratory (University Teaching Hospital, Lusaka). This laboratory which is run with the help of Japanese International Co-operation Agency (JICA), is the main laboratory for the country and maintains strict quality assurance schedule. 


\section{Analysis}

Intercooled Stata version 8 (College Station, Texas, USA) was used and the cluster effect accounted for in the analyses. Prevalence was standardised for age using the national census (2000) in order to control for changes in the age structure between surveys. The Mantel-Haenszel chi square test with continuity correction was used to test for linear trends. Multiple logistic regression analyses were used to assess and estimate the sex and residence specific changes in odds of infection between 1995 to 2003 per strata using 1995 as the reference time. A mobility index (high or low) was constructed based on frequency of travel out of usual residence and duration a respondent lived at current residence. People who travelled out of station frequently and had lived at current residence for less than or equal to two years were labelled to have a higher mobility index. This group of people was used as a proxy group for the respondents who were absent during the surveys. Conversely, people who travelled out of their station rarely and lived in the current residence for $\geq 6$ years were coded to have a lower mobility index. The distribution of age as a continuous variable conformed to normality as assessed by probability plots. Interactions were looked for using the likelihood ratio test and when identified, the terms were computed to allow estimation of the statistical effect of one of the variables separately for each level of the effect-modifying variable. Model diagnostics were done using the maximum likelihood estimation (MLE) and the Hosmer-Lemeshow goodness-of-fit. The variables in the model were age (for 15-24 years group) or age group (for 15-49 years category) with marital status, religion, employment status, travel history, length of time lived in current residence, migration origin (from town or village), and birth history for women, stratified by sex and residence. Although analyses were done in ages 15-59 years, the term "overall" was reserved for estimates in age group 15-49 years only.

\section{Ethics}

The survey protocol received clearance from the National AIDS Research Council and the University of Zambia Research Ethics Committee. In addition, participation in the population-based HIV survey was based on informed oral consent except in 2003 when written consent was obtained. Respondents were counselled and informed that the testing was purely for research purposes and was to be handled anonymously. However, respondents who were interested to know their status were offered voluntary counselling and testing (VCT) and a blood specimen was collected for serum-based HIV testing. Unlike in 1995 and 1999 surveys, when respondents were offered VCT either at the clinic and or at home respectively, in 2003 VCT was only provided at home in light of acceptability findings of an earlier study[20].

\section{Results \\ Participation and distribution}

Details of participation in the 1995-6 and 1998-9 population-based surveys have already been published and overall refusal rates were less than $10 \%$ in both surveys[10,17]. In 2003, 2705 rural residents (1301 men; 1404 females) and 4086 urban residents (1861 men; 2225 females) were listed. Non-participation was due to absence $(19.7 \%)$, interview refusals $(3.4 \%)$ or refusal to give a saliva sample for HIV testing (6.6\%). Those absent (mostly either at school, in hospital or travelled out temporarily) were $25.5 \%$ (334) of the rural males, $11.8 \%$ (166) in rural females, $28.3 \%$ (527) among urban males and $14 \%$ (311) in urban females. Of the de facto eligible and successfully interviewed population of rural males, rural females, urban males and urban females, saliva refusal rates were $3.6 \%, 5.6 \%, 9.8 \%$ and $11.1 \%$ respectively. Only the respondents that had completed the interview, tested for HIV infection and aged 15-59 years $(\mathrm{n}=$ $4751,56 \%$ urban and 44\% rural) were included in the final analysis in 2003 (Table 1).

\section{Age-specific HIV infection trends}

Overall, HIV prevalence declined during this period irrespective of sex or residence (table 2). In urban groups aged 15-49 years, prevalence declined by 41\% (21.4\%, $18.3 \%$ to $12.6 \% ; \mathrm{P}<0.001)$ in males and by $27 \%(29.6 \%, 27.0 \%$ to $21.7 \% ; \mathrm{P}<0.001)$ in females. In the rural area, the declines were not statistically significant neither in males $(15.3 \%, 13.3 \%$ to $13.0 \% ; \mathrm{P}=0.314)$ nor females $(17.4 \%$, $14.4 \%$ to $14.1 \% ; \mathrm{P}=0.118)$. In young people aged $15-24$ years, prevalence declined by $44 \%$ (5.7\%, $7.5 \%$ to $3.2 \%$; $\mathrm{P}=0.143)$ among males and by $58 \%$ (16.1\%, $10.3 \%$ to $6.8 \% ; \mathrm{P}<0.001)$ in females in the rural area. Similarly, it declined by $54 \%(6.9 \%, 7.4 \%$ to $3.2 \%$; $\mathrm{P}=0.005)$ among urban males and by $44 \%(22.5 \%, 18.3 \%$ to $12.5 \%$; $\mathrm{P}<$ 0.001 ) in urban females. The age-specific HIV infection patterns showed a diverse picture. In age 40-49 and 5059 years, prevalence increased in rural men but was stable in urban males. In rural females, prevalence declined in age groups 15-19 and 20-24 years and stabilised in groups aged 25 and above. However, in urban females, prevalence declined in groups under 30 years and stabilised in the 30-39 years old groups. Figure 1 illustrates this differential age-specific HIV prevalence declines further and worthy noting is the parallel decreasing prevalence by sex in young people by 2003 (figure 1).

\section{HIV infection trends by other socio-demographic characteristics \\ Level of education}

In the urban group, aged 15-24 years with $\geq 10$ school years, prevalence declined in both males $(9.3 \%, 6.5 \%$ to $2.1 \% ; \mathrm{P}<0.001 ;$ AOR 0.29 95\%CI $0.14-0.60)$ and females $(22.5 \%, 13.4 \%$ to $8.7 \%$; $<0.001$; AOR 0.38 
Table I: Overall (Age group, $\geq 15$ years) participation and response rates (percentages) of the population-based surveys conducted between 1995-2003 in selected rural and urban areas of Zambia

\begin{tabular}{|c|c|c|c|c|}
\hline & & 1995 & 1999 & 2003 \\
\hline Listed & & 5847 & 6235 & 6791 \\
\hline Absent & & 927 (15.9\%) & $1763(28.3 \%)$ & $1346(19.8 \%)$ \\
\hline De facto eligible (found) & & 4920 & 4472 & 5445 \\
\hline Refused interview & & $108(2.2 \%)$ & $53(1.2 \%)$ & $185(3.4 \%)$ \\
\hline Interviewed & & $4812(97.8 \%)$ & $4419(98.4)$ & $5260(96.6 \%)$ \\
\hline \multirow[t]{4}{*}{ Saliva test } & Accepted & 4499 (93.5\%) & 4021 (91\%) & 4913 (93.4\%) \\
\hline & Refused & $28 \mathrm{I}(5.8 \%)$ & $397(9 \%)$ & $347(6.6 \%$ \\
\hline & Lost & $32(0.7 \%)$ & -- & -- \\
\hline & Damaged/Mislabelled & 162 & 264 & 162 \\
\hline Sample (Interviewed \& tested, Less damaged/mislabelled) $\S$ & & 4337 (88.2\%) & $3757(84 \%)$ & $4751(87.3 \%)$ \\
\hline Final sample age $15-59$ years & & 3158 & 3731 & 4751 \\
\hline Response (\%) (Listed-[absent+refusals]/listed*100) & & $77.4 \%$ & $64.5 \%$ & $72.3 \%$ \\
\hline
\end{tabular}

Notes: I. §Percentages in the final sample analysed represents proportion of participation out of the de facto eligible population. This includes respondents aged $\geq 60$ years in 1995 \& 1999. 2. Information by sex was incomplete in the file linking the listed and interviewed respondents.

95\%CI 0.19-0.79), table 3. Overall, the proportion with $\geq 10$ school years (secondary education) was $7 \%, 6.5 \%$ and $11 \%$ in the rural area and $32 \%, 43 \%$ and $55 \%$ in the urban area in 1995, 1999 and 2003 respectively. The effect of education was significantly different between age groups (interaction $\mathrm{P}=0.021$ in $1995, \mathrm{P}<0.001$ in 1999 $\& 2003)$. In the rural and urban groups aged $15-49$ years, higher educated groups had lower odds of infection by 2003 in both sexes. No statistically significant trends were observed in neither young nor older respondents with 07 years of schooling (see table 4 ).

\section{Marital status}

In age 15-24, although married men had higher likelihood of infection than single respondents in both rural (AOR 2.31 95\% CI 1.16-4.59) and urban areas (AOR $2.8295 \%$ CI 2.1-3.83) in 1995, prevalence declined significantly in both rural $(12.5,11.3$ to $5 \%)$ and urban $(22.2,14.3$ to $8.3 \%)$ areas although the distribution by marital status did not change over the survey periods. In married females, prevalence declined also in both the rural $(20.5,10.0$ to $7.6 \%)$ and urban areas $(38.9,26.0$ to $22.5 \%$ ). Similarly, prevalence declined significantly in urban married respondents aged 15-49 years (men, $\mathrm{P}=$ 0.035; women, $\mathrm{P}=0.002$ ), see Table 4 .

\section{Employment}

Overall, men were more likely to be employed in both rural and urban areas. Although, employment was associated with increased likelihood of HIV infection in 2003 among rural males overall, AOR 1.67(95\%CI 1.14-2.45), prevalence decline significantly irrespective of employment status in both sexes in the urban areas. In age 15-24 years, prevalence declined in all employment categories in both the rural and urban areas.

\section{Mobility factors}

In the age group 15-24 years, there were no significant differences in HIV prevalence patterns by mobility status. However, in age 15-49, the likelihood of infection among the more mobile groups tended to be higher than among the less mobile groups in men, AOR 1.45 (95\%CI 0.982.18 ) in $1995,1.75$ (95\%CI $1.17-2.6)$ in 1999 and 1.84 (95\%CI 1.31-2.58) in 2003. Over the period, and among groups with higher mobility index, there was significant prevalence decline in the urban areas, but was non-significant in the rural area (men: $19.1 \%, 12.6 \%$ to $16.3 \% ; \mathrm{P}=$ 0.255 ; women: $20.0 \%, 15.9 \%$ to $16.4 \%, P=0.289$ ), see table 5 . In respondents with $\geq 11$ school years, the likelihood of infection was higher among mobile men in the urban area groups in 1995 (AOR 1.29 95\%CI 0.53-3.16), 1999 (AOR 2.38 95\%CI 1.1-5.27) and in 2003 (AOR $3.5495 \%$ CI 1.41-8.86) than less mobile respondents. However, there were parallel prevalence declines in both the mobile (34\%, 26.5\% 14.5\%, $\mathrm{P}<0.001)$ and the less mobile group.

\section{Fertility}

The likelihood of infection in females aged 15-24 years who had given birth ever was higher than those who had never given birth in both rural (AOR 1.44 95\%CI 0.563.7) and urban areas (OR 2.61 95\%CI 1.71-3.99) in 1995. However, prevalence declined in both the group ever given birth (rural, $\mathrm{P}=0.005$; urban, $\mathrm{P}=0.002$ ) and the rural respondents who had never given birth $(\mathrm{P}=$ $0.001)$.

\section{Parallel behaviour changes in higher educated young people}

Table 6 illustrates some of the corroborative sexual behaviour parallel changes observed in higher educated urban 
Table 2: Population based age-specific prevalence differential trends of HIV infection by sex in Chelstone, Lusaka and Kapiri Mposhi, Zambia: I995-2003

Sex Age group (years) Age-specific Prevalence, \% (total number of respondents, $n$ )

Rural Urban

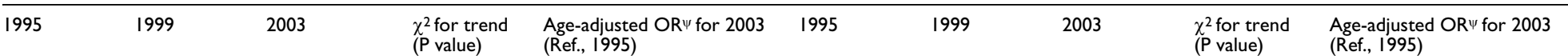

Males $\quad 15-19$

15-19

$5.5(73)-5.4(129)-2.1(146)-0.16$

$25-29$

$5.4(129) \quad 2.1(146)$

0.161

$4.5(266)$

30-39

20.9(67)

$13.2(114)$

$4.3(163)$

0.468

$10.7(168)$

$6.3(224)$

$2.2(314)$

0.144

$40-49$
$50-59$

$31.9(91)$

$23.1(169)$

$20.8(235)$

0.127

$33.3(114)$

$8.6(208)$

$4.2(309)$

0.144
0.006

$\begin{array}{llll}41.5(106) & 40.2(82) & 33.3(78) & 0.276\end{array}$

$14.6(48)$

$9.3(92)$

17.9(89)

0.036
0.416

26.5(34)

13.5(37)

25.8(66)

0.847

15-24

Crude

Adjusted $\dagger$

$5.7(176)$

$7.5(268) \quad 3.2(309)$

0.143

$0.56(0.25-1.26)$

$\begin{array}{llll}6.9(434) & 7.4(432) & 3.2(623) & \mathbf{0 . 0 0 5} \\ 7.5 & 7.4 & 3.2 & \mathbf{0 . 0 0 1} \\ 3.12 & 2.47 & 3.87 & \end{array}$

$\begin{array}{lll}2.8 & 1.46 & 2.06 \\ 1.34 & 1.03 & 1.03\end{array}$

15-49

Crude 153(399) 133(652)

$\begin{array}{llll}\text { Adjusted } \dagger & 15.3(399) & 13.3(652) & 13.0(8) \\ \text { FM ratio } & 15.4 & 12.8 & 11.6\end{array}$

F:M ratio

1.12

Urban:Rural ratio

$\begin{array}{ll}1.10 & 1.15\end{array}$

$0.80(0.55-1.18)$

-..-

Females 15-19

$15-19$

$\begin{array}{lll}8.2(122) & 5.9(217) & 3.1(223) \\ 24.6(114) & 15.9(163) & 10.3(233) \\ 17.7(79) & 20.6(60) & 18 .(187)\end{array}$

$\begin{array}{lll}8.2(122) & 5.9(217) & 3.1(223) \\ 24.6(114) & 15.9(163) & 10.3(233) \\ 17.7(79) & 20.6(60) & 18 .(187)\end{array}$

$\begin{array}{lll}8.2(122) & 5.9(217) & 3.1(223) \\ 24.6(114) & 15.9(163) & 10.3(233) \\ 17.7(7) & 20.6(160) & 182(87)\end{array}$

$10.3(233)$

$17.7(79) \quad 20.6(160)$

$23.8 \%(256)$

$30-39$

19.8(III) $\quad 18.4(233)$

$23.8 \%(256)$
$14.7(156)$

$17.8(73)$

$11.7(120)$

$5.3(94)$

0.072

$\begin{array}{llll}21.4(804) & 18.3(743) & 12.6(1042) & \mathbf{0 . 0 0 0} \text { ** } \\ 24.8 & 18.3 & 16.9 & \mathbf{0 . 0 0 0} \\ 1.23 & 1.49 & 1.35 & \\ ---- & ---- & ---- & \end{array}$

$0.58(0.38-0.87)$

50-59

15-24

Crude

Adjustedt

16.1(236)

$10.3(380) \quad 6.8(456)$

0.000**

$0.36(0.19-0.67)$

12.3(391)

9.5(336)

$7.7(431)$

0.026

0.039
0.001

$35.4(311)$
$48.7(199)$

27.9(305)

$7.7(431)$

0.026

0.929

$34.5(310)$

$41.2(221) \quad 31.1(286)$

$0.000 * *$

0.140

$26.0(100)$

$39.6(273)$

0.202

$\begin{array}{llll}26.0(100) & 22.3(I \mid 2) & 22.9(148) & 0.614 \\ 0(I I) & 25.0(I 2) & 13.9(36) & 0.444\end{array}$

Urban:Rural ratio $\quad 1.49$

15-49

Crude 17.4(499)

Adjustedt 173

Urban:Rural ratio

17.3
1.78

$\begin{array}{lll}10.5 & 6.4 & \mathbf{0 . 0 0 0} * *\end{array}$

\begin{tabular}{llll}
$22.5(702)$ & $18.3(64 I)$ & $12.5(840)$ & $\mathbf{0 . 0 0 0 * *}$ \\
23.4 & 18.3 & 12.4 & $\mathbf{0 . 0 0 0 * *}$ \\
\hdashline--- & $-\cdots$ & ---- & \\
& & & \\
$29.6(13 \mid I)$ & $27.0(1218)$ & $21.7(1547)$ & $\mathbf{0 . 0 0 0 * *}$ \\
30.6 & 27.3 & 22.8 & $\mathbf{0 . 0 0 0 * *}$
\end{tabular}

$0.43(0.33-0.57)$

$1.74 \quad 1.94$

$14.4(893) \quad 14.1(1055) \quad 0.118$

0.118

$0.76(0.47-1.23)$

30.6

1.94

1.70

Notes I. † Denotes standardised prevalence using the Zambia National Census for the year 2000 as reference population 2. OR $\psi$ stands for Odds ratio given with $95 \%$ Confidence Interval and adjusted with age as a continuous variable and confidence interval adjusted for clustering effect using Intercooled Stata version 8 with the Standard Enumeration Area (SEA) as clusters. Statistically significant OR, highlighted in bold 3. Chi square for linear trend, Extended Mantel-Haenszel ( 1 degree of freedom) with continuity correction was used: a) Statistically significant trends are highlighted in bold b) $* *$ denotes $P<0.001$ 4. Sample sizes were $n=3158$ in 1995, 3731 in 1999 \& 4751 in 2003 (age group 15-59 years). 

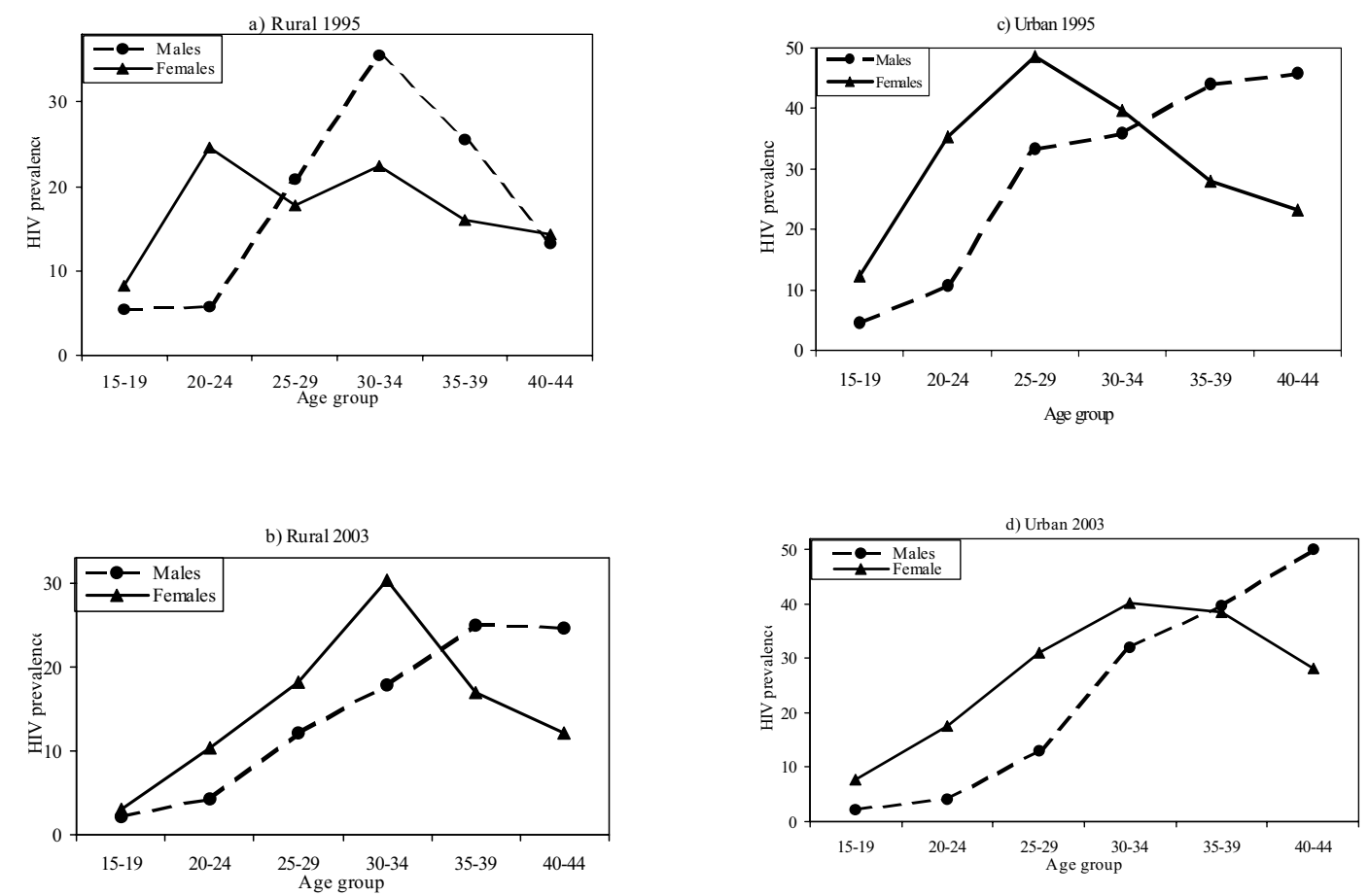

Sample size: Sample sizes were $\mathrm{n}=3158$ in 1995, 3731 in $1999 \& 4751$ in 2003 (age group 15-59 years)

\section{Figure I}

Age-specific HIV prevalence in rural and urban areas, illustrating cross-generational differences by sex: 1995 and 2003 . This figure further illustrates the HIV prevalence declines by sex. Key to this are the increased age cross-over points, that's is, the point at which the HIV prevalence in young women which is usually higher than young men, is over taken by the prevalence in young men. Consequently we see a picture where after age 30s, HIV prevalence in men is higher than in women. Sexual relationships between these infected men and younger women under age 25 are probably the main force driving the HIV epidemic in sub-Saharan Africa.

young people where there was declining HIV prevalence. The reported use of a condom during the last casual sex among young people with $\geq 11$ school years increased from $42.7 \%$ to $67.3 \%$, adjusted OR $2.9695 \%$ CI $1.93-$ 4.52 between 1995 and 2003 in comparison with groups with 0-7 school years. Similarly, higher educated young reported less number of casual sexual partners in the last twelve months than groups with $0-7$ school years in 2003, AOR 0.33 95\%CI 0.19-0.56. The observed changes in the rural area however, were less prominent although present.

\section{Discussion}

A steep HIV prevalence decline was observed in young men and women aged 15-24 years in the studied populations. Prevalence declined also in urban men and women aged 25-29 years, whereas it was mostly stable in older age groups. In age group 15-49 years, a marked prevalence decline appeared in urban men and women, but the rural decline was modest and not significant. HIV-related mortality is likely to have contributed substantially to the overall decline. A 3-years cohort study based on the 1995 survey found HIV-related mortality to be generally low among young people, except in urban young women where HIV was found to have already affected mortality substantially (unpublished). In the absence of incidence data which was not possible to collect in this study due to ethical limitations, the observed prevalence declines in young people can be a proxy of change in incidence, and selective mortality seemed only to represent a small proportion of the steep decline in young urban women[21]. Similar patterns of declines have been reported in the 
Table 3: Trends in HIV prevalence by selected socio-demographic characteristics in rural and urban areas of Zambia, results of multivariate logistic regression and chi square tests for linear trend, 1995-2003: Age group I 5-24 years

\begin{tabular}{|c|c|c|c|c|c|c|c|c|}
\hline & & & Males & & & Females & & \\
\hline & & & $\begin{array}{l}\text { Adjusted Odds Ratio( } 95 \% \mathrm{Cl}) \text { : } \\
\text { reference time, } 1995\end{array}$ & & $\begin{array}{l}\S M H \chi^{2} \text { for Linear } \\
\text { trend, 1995-2003: }\end{array}$ & $\begin{array}{l}\text { Adjusted Odds Ratio(95\% } \mathrm{Cl}) \text { : } \\
\text { reference time, } 1995\end{array}$ & & $\begin{array}{l}\S M H \chi^{2} \text { for Linear } \\
\text { trend, 1995-2003: }\end{array}$ \\
\hline & & & 1999 & 2003 & $P$ value & 1999 & 2003 & $P$ value \\
\hline \multirow[t]{2}{*}{$\mathbf{R}$} & Education ( age) $\ddagger$ & & & & & & & \\
\hline & & $0-7$ years & $2.05(0.63-6.61)$ & $0.69(0.17-2.80)$ & 0.495 & $0.66(0.34-1.26)$ & $0.43(0.19-0.93)$ & 0.084 \\
\hline \multirow[t]{2}{*}{$\mathbf{u}$} & & 8-9 years & $0.84(0.34-2.04)$ & $0.40(0.09-1.78)$ & 0.670 & $0.86(0.38-1.93)$ & $0.25(0.05-1.26)$ & 0.002 \\
\hline & & $\geq 10$ years & $1.26(0.11-13.8)$ & $0.16(0.11-0.25)$ & 0.113 & $0.29(0.08-11.1)$ & $0.10(0.01-7.34)$ & 0.004 \\
\hline \multirow[t]{2}{*}{$\mathbf{R}$} & Marital status & Single & $1.57(0.57-4.36)$ & $0.58(0.21-1.64)$ & 0.383 & I.45(0.29-7.24) & $0.36(0.04-2.98)$ & 0.028 \\
\hline & & Married & $0.79(0.22-2.88)$ & $0.14(0.02-1.30)$ & 0.187 & $0.42(0.23-0.76)$ & $0.29(0.13-0.68)$ & $0.001 *$ \\
\hline \multirow[t]{3}{*}{ A } & Employed & Yes & $0.75(0.36-1.59)$ & $0.38(0.13-1.09)$ & 0.194 & $1.59(0.15-17.2)$ & $0.43(0.04-5.01)$ & 0.215 \\
\hline & & No & $2.30(0.77-6.90)$ & $0.44(0.13-1.56)$ & 0.338 & $0.65(0.37-1.13)$ & $0.33(0.14-0.78)$ & $0.001 *$ \\
\hline & Travels & Never & $1.79(0.65-4.92)$ & $0.68(0.31-1.48)$ & 0.496 & $0.56(0.9-1.58)$ & $0.35(0.13-0.97)$ & 0.089 \\
\hline \multirow[t]{9}{*}{$\mathbf{L}$} & & Sometimes & I.06(0.4I-2.77) & $0.18(0.05-0.60)$ & 0.259 & $0.62(0.27-1.45)$ & $0.27(0.11-0.68)$ & $0.001 *$ \\
\hline & & Often & $1.21(0.49-2.99)$ & $0.44(0.15-1.33)$ & 0.396 & $0.47(0.16-1.39)$ & $0.21(0.01-4.91)$ & 0.113 \\
\hline & Duration lived & $<$ I year & $\#^{*}$ & $0.32(0.01-22.1)$ & 0.649 & $0.33(0.08-1.39)$ & $0.4 I(0.08-2.14)$ & 0.087 \\
\hline & (In current residence) & $1-5$ yrs & I.77(0.53-5.92) & $0.65(0.12-3.41)$ & 0.565 & $0.85(0.39-1.88)$ & $0.34(0.12-0.97)$ & 0.058 \\
\hline & & $\geq 6 \mathrm{yrs}$ & $1.92(0.43-8.56)$ & $0.28(0.03-2.31)$ & 0.184 & $0.5 \mathrm{I}(0.15-\mid .72)$ & $0.23(0.08-0.69)$ & 0.003 \\
\hline & Migration & Village & $1.12(0.42-2.99)$ & $1.07(0.30-3.79)$ & 0.711 & $0.44(0.21-0.90)$ & $0.18(0.06-0.55)$ & 0.002 \\
\hline & (origin 5 years) & Town & $0.59(0.03-9.98)$ & $0.01(0.00-0.13)$ & 0.456 & $1.46(0.32-6.52)$ & $0.75(0.20-2.77)$ & 0.494 \\
\hline & Given birth & Yes & -- & -- & & $0.65(0.39-1.08)$ & $0.42(19-0.89)$ & 0.005 \\
\hline & (ever): age, 15-24 & No & -- & -- & & $0.45(0.21-0.96)$ & $0.09(0.02-0.5 I)$ & 0.001 \\
\hline \multirow[t]{2}{*}{$\mathbf{u}$} & Education ( age) $\ddagger$ & & & & & & & \\
\hline & & $0-7$ years & $6.69(2.47-18.1)$ & $1.45(0.22-9.40)$ & 0.634 & $0.65(0.39-1.07)$ & $0.79(0.43-1.43)$ & 0.674 \\
\hline \multirow[t]{2}{*}{$\mathbf{R}$} & & $8-9$ years & $0.42(0.06-2.78)$ & $0.57(0.22-1.49)$ & 0.885 & $1.20(0.66-2.18)$ & $0.59(0.33-1.07)$ & 0.110 \\
\hline & & $\geq 10$ years & $0.94(0.45-1.95)$ & $0.29(0.14-0.60)$ & $0.001 *$ & $0.79(0.34-1.79)$ & $0.38(0.19-0.79)$ & $0.001 *$ \\
\hline \multirow[t]{2}{*}{ B } & Marital status & Single & $1.29(0.66-2.53)$ & $0.56(0.32-0.95)$ & 0.011 & $1.09(0.68-1.74)$ & $0.57(0.36-0.88)$ & 0.002 \\
\hline & & Married & $1.03(0.69-1.55)$ & $0.70(0.46-1.06)$ & 0.306 & $0.49(0.30-0.80)$ & $0.38(0.25-0.58)$ & 0.003 \\
\hline \multirow[t]{2}{*}{ A } & Employed & Yes & $1.89(0.35-10.2)$ & $0.98(0.25-3.93)$ & 0.454 & $1.02(0.39-2.66)$ & $0.4 I(0.19-0.86)$ & 0.232 \\
\hline & & No & $1.07(0.5 \mathrm{I}-2.23)$ & $0.4 \mid(0.23-0.73)$ & 0.003 & $0.86(0.56-1.32)$ & $0.53(0.34-0.83)$ & $0.001 *$ \\
\hline \multirow[t]{10}{*}{$\mathbf{N}$} & Travels & Never & I. $12(0.48-2.60)$ & $0.79(0.34-1.87)$ & 0.208 & $0.96(0.66-1.40)$ & $0.58(0.39-0.85)$ & 0.025 \\
\hline & & Sometimes & $1.45(0.34-6.19)$ & $0.16(0.04-0.7 I)$ & 0.003 & $0.86(0.5 \mathrm{I}-\mathrm{I} .45)$ & $0.46(0.26-0.8 I)$ & $0.001 *$ \\
\hline & & Often & $0.86(0.13-5.63)$ & $0.99(0.19-5.21)$ & 0.983 & $0.38(0.02-9.51)$ & $0.32(0.06-1.84)$ & $0.001 *$ \\
\hline & Duration lived & $<1$ year & $4.67(0.93-23.2)$ & $0.51(0.16-1.62)$ & 0.571 & $0.87(0.44-1.74)$ & $0.66(0.33-1.35)$ & 0.638 \\
\hline & (In current residence) & $\mathrm{I}-5 \mathrm{yrs}$ & $0.63(0.23-1.72)$ & $0.33(0.16-0.69)$ & 0.034 & $0.68(0.48-0.96)$ & $0.42(0.26-0.67)$ & $0.001 *$ \\
\hline & & $\geq 6$ yrs & $1.60(0.22-11.5)$ & $1.38(0.23-8.26)$ & 0.353 & $1.26(0.46-3.40)$ & $0.47(0.15-1.45)$ & $0.001 *$ \\
\hline & Migration & Village & $1.49(0.37-6.12)$ & $0.46(0.07-2.98)$ & 0.902 & $1.19(0.32-4.45)$ & $1.09(0.24-4.99)$ & 0.865 \\
\hline & (origin 5 years) & Town & $1.08(0.31-3.74)$ & $0.38(0.18-0.79)$ & 0.068 & $0.7 \mid(0.48-1.08)$ & $0.47(0.30-0.74)$ & $0.001 *$ \\
\hline & Given birth & Yes & -- & -- & & $0.65(0.51-0.86)$ & $0.47(0.30-0.74)$ & 0.002 \\
\hline & (ever): age, 15-24 & No & -- & -- & & $0.96(0.67-1.38)$ & $0.65(0.4 I-0.98)$ & 0.129 \\
\hline
\end{tabular}

Notes: I. \$MH denotes Mantel-Haenszel chi square for linear trend, ( I degree of freedom) with continuity correction and statistically significant trends are highlighted in bold b) *signifies $\mathrm{P}<0.00 \mathrm{I} \mathbf{2}$ Variables included in the model per strata were age, marital status, employment, religion, travel patterns, duration lived in current residence, migration origin in last five years and ever given birth for females 3. $¥$ The effect of education was significantly different between age groups (interaction $P=0.021$ in 1995, $P<0.001$ in 1999\&2003), hence the "age*education" interaction term included in the models. 4. Samples size in 1995, 1999 and 2003 and were 1548, I72I and 2228 respectively 5. \#* No respondent had HIV in I999 (n=32) 
Table 4: Trends in HIV prevalence by selected socio-demographic characteristics in rural and urban areas of Zambia, results of multivariate logistic regression and chi square tests for linear trend, 1995-2003: Age group 15-49 years

\begin{tabular}{|c|c|c|c|c|c|c|c|c|}
\hline & & & Males & & & Females & & \\
\hline & & & $\begin{array}{l}\text { Adjusted Odds Ratio( }(95 \% \mathrm{Cl}) \text { : } \\
\text { reference time, } 1995\end{array}$ & & $\begin{array}{l}\S M H \chi^{2} \text { for Linear } \\
\text { trend, 1 199-2003: }\end{array}$ & $\begin{array}{l}\text { Adjusted Odds Ratio }(95 \% \mathrm{Cl}) \text { : } \\
\text { reference time, } 1995\end{array}$ & & $\begin{array}{l}\S M H \chi^{2} \text { for Linear } \\
\text { trend, 1995-2003: }\end{array}$ \\
\hline & & & 1999 & 2003 & $P$ value & 1999 & 2003 & $P$ value \\
\hline \multirow[t]{2}{*}{$\mathbf{R}$} & Education ( age) $\ddagger$ & & & & & & & \\
\hline & & $0-7$ years & $0.93(0.62-1.34)$ & $0.72(0.47-1.09)$ & 0.227 & $1.07(0.57-2.01)$ & $1.03(0.62-1.72)$ & 0.838 \\
\hline \multirow[t]{2}{*}{ u } & & $8-9$ years & $0.74(0.29-1.88)$ & $0.84(0.28-2.46)$ & 0.731 & $0.52(0.24-1.13)$ & $0.50(0.22-1.14)$ & 0.104 \\
\hline & & $\geq 10$ years & $0.38(0.15-0.98)$ & $0.44(0.22-0.87)$ & 0.223 & $0.33(0.17-0.65)$ & $0.29(0.08-0.96)$ & 0.043 \\
\hline \multirow[t]{2}{*}{$\mathbf{R}$} & Marital status & Single & $1.48(0.76-2.86)$ & $0.50(0.22-1.12)$ & 0.188 & $0.74(0.23-2.4)$ & $0.3 \mathrm{I}(0.06-1.49)$ & 0.021 \\
\hline & & Married & $0.66(0.38-1.15)$ & $0.63(0.42-0.96)$ & 0.096 & $0.91(0.53-1.57)$ & $0.82(0.49-1.37)$ & 0.112 \\
\hline \multirow[t]{3}{*}{ A } & Employed & Yes & $0.66(0.42-1.03$ & $0.76(0.48-1.21$ & 0.914 & $0.8 \mathrm{I}(0.2 \mathrm{I}-3.15)$ & $0.73(0.22-2.42)$ & 0.479 \\
\hline & & No & $1.03(0.57-1.84)$ & $0.55(0.34-0.89)$ & 0.026 & $0.82(0.48-1.38)$ & $0.78(0.47-1.31)$ & 0.055 \\
\hline & Travels & Never & $0.99(0.52-1.91)$ & $1.36(0.86-2.16)$ & 0.180 & $0.93(0.54-1.60$ & $1.09(0.70-1.71)$ & 0.644 \\
\hline \multirow[t]{9}{*}{$\mathbf{L}$} & & Sometimes & $0.66(0.44-0.98)$ & $0.43(0.27-0.70)$ & 0.019 & $0.76(0.33-1.71)$ & $0.59(0.31-1.10)$ & 0.024 \\
\hline & & Often & $0.76(0.2 I-2.75)$ & $0.62(0.19-1.94)$ & 0.563 & $0.92(0.23-3.67)$ & $0.44(0.07-2.89)$ & $0.05 I$ \\
\hline & Duration lived & $<1$ year & $0.25(.10-0.63)$ & $0.63(0.22-1.81$ & 0.733 & $0.57(0.33-0.99)$ & $0.79(0.35-1.82)$ & 0.199 \\
\hline & (In current residence) & $\mathrm{I}-5 \mathrm{yrs}$ & $0.74(0.36-1.52)$ & $0.57(0.26-1.28)$ & 0.069 & $1.79(0.88-3.62)$ & $\mid .4 \mathrm{I}(0.74-2.69)$ & 0.234 \\
\hline & & $\geq 6$ yrs & $1.24(0.76-2.03)$ & $0.95(0.60-1.5 I)$ & 0.937 & $0.45(0.23-0.89)$ & $0.48(0.26-0.88)$ & 0.011 \\
\hline & Migration & Village & $0.72(0.43-1.22)$ & $0.99(0.51-1.94)$ & 0.922 & $1.12(0.58-2.16)$ & $1.04(0.55-1.97)$ & 0.840 \\
\hline & (origin 5 years) & Town & $0.48(0.22-0.98)$ & $0.30(0.13-0.72)$ & 0.041 & $1.75(0.99-3.01)$ & I.3I (0.75-2.32) & 0.586 \\
\hline & Given birth & Yes & -- & -- & & $0.75(0.42-1.34)$ & $0.58(0.30-1.1 \mathrm{I})$ & 0.019 \\
\hline & (ever): age, 15-29 & No & -- & -- & & $0.56(0.23-1.33)$ & $0.27(0.07-0.99)$ & 0.012 \\
\hline \multirow[t]{2}{*}{ u } & Education ( age) $\ddagger$ & & & & & & & \\
\hline & & $0-7$ years & $1.66(0.80-3.42)$ & $1.34(0.72-2.49)$ & 0.398 & $0.83(0.59-1.16)$ & I.II(0.7I-I.76) & 0.498 \\
\hline \multirow[t]{2}{*}{$\mathbf{R}$} & & $8-9$ years & $0.42(0.14-1.26)$ & $0.52(0.26-1.06)$ & 0.305 & $1.10(0.76-1.61)$ & $0.66(0.39-1.08)$ & 0.179 \\
\hline & & $\geq 10$ years & $1.03(0.72-1.49)$ & $0.55(0.40-0.74)$ & $0.001 *$ & $0.91(0.61-1.34)$ & $0.53(0.39-0.72)$ & $0.001 *$ \\
\hline \multirow[t]{2}{*}{ B } & Marital status & Single & $0.95(0.62-1.46)$ & $0.5 I(0.33-0.79)$ & $0.001 *$ & $1.05(0.69-1.58)$ & $0.49(0.35-0.69)$ & $0.001 *$ \\
\hline & & Married & $1.04(0.72-1.52)$ & $0.7 I(0.47-0.98)$ & 0.035 & $0.92(0.74-1.14)$ & $0.73(0.57-0.94)$ & 0.002 \\
\hline \multirow[t]{2}{*}{ A } & Employed & Yes & $0.97(0.69-1.36)$ & $0.64(0.44-0.95)$ & 0.001 & $0.98(0.67-I .4 I)$ & $0.69(0.5 I-0.95)$ & 0.018 \\
\hline & & No & $0.99(0.60-1.64)$ & $0.52(0.37-0.74)$ & $0.001 *$ & $0.93(0.76-1.15)$ & $0.63(0.47-0.85)$ & $0.001 *$ \\
\hline \multirow[t]{10}{*}{$\mathbf{N}$} & Travels & Never & $0.81(0.57-1.16)$ & $0.57(0.32-1.02)$ & 0.001 & $0.88(0.70-1.1 \mathrm{I})$ & $0.64(0.49-0.83)$ & 0.003 \\
\hline & & Sometimes & I.I4(0.86-1.49) & $0.52(0.34-0.81)$ & $0.001 *$ & $1.06(0.84-1.35)$ & $0.71(0.52-0.97)$ & 0.008 \\
\hline & & Often & I.II (0.55-2.2I) & $0.80(0.38-1.70)$ & 0.189 & $0.77(0.23-2.59)$ & $0.44(0.23-0.82)$ & 0.002 \\
\hline & Duration lived & $<1$ year & $1.62(0.83-3.19)$ & $0.47(0.28-0.76)$ & 0.052 & $0.83(0.54-1.27)$ & $0.66(0.45-0.97)$ & 0.196 \\
\hline & (In current residence) & $1-5$ yrs & $0.85(0.54-1.35)$ & $0.71(0.47-1.09)$ & 0.007 & $0.83(0.59-1.16)$ & $0.56(0.40-0.79)$ & $0.001 *$ \\
\hline & & $\geq 6$ yrs & $0.90(0.56-1.46)$ & $0.53(0.29-0.99)$ & $0.001 *$ & $1.3 \mathrm{I}(0.95-1.8 \mathrm{I})$ & $0.86(0.57-1.33)$ & 0.129 \\
\hline & Migration & Village & $1.01(0.39-2.59)$ & $0.39(0.09-1.54)$ & 0.314 & $0.98(0.42-2.32)$ & $0.93(0.42-2.09)$ & 0.651 \\
\hline & (origin 5 years) & Town & $1.03(0.63-1.68)$ & $0.69(0.49-0.96)$ & 0.001 & $0.83(0.64-1.06)$ & $0.58(0.45-0.74)$ & $0.001 *$ \\
\hline & Given birth & Yes & -- & -- & & $0.73(0.63-0.35)$ & $0.5 I(0.38-0.67)$ & $0.001 *$ \\
\hline & (ever): age, 15-29 & No & -- & -- & & $0.87(0.64-1.19)$ & $0.52(0.35-0.75)$ & 0.042 \\
\hline
\end{tabular}

Notes: I. \$MH denotes Mantel-Haenszel chi square for linear trend, ( I degree of freedom) with continuity correction and statistically significant trends are highlighted in bold $\mathbf{b}$ ) $*$ signifies $\mathrm{P}<0.00 \mathrm{I} \mathbf{2}$. Variables included in the model per strata were age group, marital status, employment, religion, travel patterns, duration lived in current residence, migration origin in last five years and ever given birth for females 3. ¥ The effect of education was significantly different between age groups (interaction $P=0.021$ in 1995, $P<0.001$ in 1999\&2003), hence the "age*education" interaction term included in the models. 4. Samples size in 1995, 1999 and 2003 and were 3013, 3506 and 4466 respectively 
Table 5: Population-based HIV prevalence trends of groups with high mobility index "ll by sex in selected areas in Zambia, 1995-2003

\begin{tabular}{|c|c|c|c|c|c|}
\hline Sex & Residence & Year & HIV prevalence (n) & $\begin{array}{l}\text { Age-adjusted Odds Ratio (OR) } \psi \text { for likelihood of } \\
\text { HIV infection in } 1999 \text { and } 2003 \text { (Reference, 1995) }\end{array}$ & $\chi^{2}$ for linear trend ( $P$ value) \\
\hline \multirow[t]{6}{*}{ Males } & Rural & 1995 & 19.1(94) & 1.00 & 0.255 \\
\hline & & 1999 & $12.6(87)$ & $0.59(0.26-1.33)$ & \\
\hline & & 2003 & $16.3(104)$ & $0.72(0.34-1.54)$ & \\
\hline & Urban & 1995 & $23.0(226)$ & 1.00 & 0.036 \\
\hline & & 1999 & $23.4(107)$ & $0.98(0.56-1.75)$ & \\
\hline & & 2003 & $14.7(197)$ & $0.52(0.3 I-0.88)$ & \\
\hline \multirow[t]{6}{*}{ Females } & Rural & 1995 & $20.0(65)$ & 1.00 & 0.289 \\
\hline & & 1999 & I5.9(107) & $0.74(0.33-1.66)$ & \\
\hline & & 2003 & $16.4(128)$ & $0.77(0.35-1.67)$ & \\
\hline & Urban & 1995 & $35.0(314)$ & 1.00 & 0.009 \\
\hline & & 1999 & $28.1(139)$ & $0.75(0.48-1.18)$ & \\
\hline & & 2003 & $25.0(252)$ & $0.63(0.43-0.92)$ & \\
\hline
\end{tabular}

Notes I. " High mobility index was a composite measure of groups who travelled out of station frequently for any reason and have lived at current residence for less or equal to two years. 2. OR $\psi$ was adjusted for age and school years (as a continuous variable), employment status and marital status. Statistically significant OR highlighted in bold 3. Extended Mantel-Haenszel Chi square for linear trend, (I degree of freedom) with continuity correction was used; highlighted in bold is statistically significant $P$ value 4. Sample sizes were $n=585$ in rural and I235 in urban (age group I5-49 years).

Table 6: Likelihood of "condom use at last casual sex" and "having $\geq 2$ sexual partners in last 12 months" by educational attainment among urban respondents aged I5-24 years in Zambia, results of multivariate logistic regression: 1995-2003

\begin{tabular}{|c|c|c|c|c|c|c|c|}
\hline \multirow[t]{2}{*}{ Factor } & \multirow[t]{2}{*}{ Education } & \multicolumn{2}{|l|}{1995} & \multicolumn{2}{|l|}{1999} & \multicolumn{2}{|l|}{2003} \\
\hline & & $\begin{array}{l}\text { Prevalence } \\
{[\%(n)]}\end{array}$ & $\begin{array}{l}\text { Adjusted Odds } \\
\text { Ratio(95\%Cl) }\end{array}$ & $\begin{array}{l}\text { Prevalence } \\
{[\%(\mathbf{n})]}\end{array}$ & $\begin{array}{l}\text { Adjusted Odds } \\
\text { Ratio(95\%Cl) }\end{array}$ & $\begin{array}{l}\text { Prevalence } \\
{[\%(n)]}\end{array}$ & $\begin{array}{l}\text { Adjusted Odds } \\
\text { Ratio(95\%Cl) }\end{array}$ \\
\hline \multirow{3}{*}{$\begin{array}{l}\text { Condom use during the last } \\
\text { casual sex }\end{array}$} & $0-7$ years & $25.5(286)$ & 1 & $26.2(126)$ & I & $42.9(119)$ & 1 \\
\hline & $8-10$ years & $27.4(402)$ & $0.98(0.69-1.43)$ & $51.2(201)$ & $2.82(1.73-4.60)$ & $53.8(184)$ & $1.54(0.96-2.46)$ \\
\hline & $\geq 11$ years & $42.7(218)$ & $1.40(0.94-2.10)$ & $68.9(270)$ & $5.62(3.44-9.20)$ & $67.3(437)$ & $2.96(1.93-4.52)$ \\
\hline \multirow{3}{*}{$\begin{array}{l}\text { Proportion having } \geq 2 \text { sexual } \\
\text { partners, last } I 2 \text { months }\end{array}$} & $0-7$ years & $16.2(376)$ & 1 & $11.0(145)$ & 1 & $20.8(144)$ & 1 \\
\hline & 8-9 years & $16.2(469)$ & $0.76(0.5 I-I .13)$ & $18.4(228)$ & $1.48(0.78-2.82)$ & $16.7(204)$ & $0.63(0.35-1.12)$ \\
\hline & $\geq$ II years & $15.6(270)$ & $0.49(0.30-0.79)$ & $17.2(285)$ & $1.06(0.55-2.82)$ & I I.5 (442) & $0.33(0.19-0.56)$ \\
\hline
\end{tabular}

Notes: I. All confidence interval adjusted for clustering effect using Intercooled Stata version 8 with the Standard Enumeration Area (SEA) as clusters 3. Variables included in the model were education, age, sex, marital status, employment and religion. 2. Samples sizes (were drawn from groups ever had sex). 
region recently[1,2,5,13,22]. Furthermore, the declines were strongest in groups with secondary school education or more and were associated with sexual behavioural change.

It is possible that differential infection patterns among non-participants over time could have biased our estimates, but the magnitude and direction of this effect can only to some extent be assessed[2]. The non-participation due to refusal to provide saliva remained low in all survey rounds, and significantly below refusal levels as experienced in the Demography and Health Survey in Zambia 2001/2002 when using blood as the basis for HIV testing [16]. Absence was the most significant cause of non-participation, particularly in men. We think that the group of participants reporting to be highly mobile could be used as sentinel of HIV infection for men who were absent. Mobility and migration have been suggested to be factors fueling HIV transmission, but there are relatively few studies documenting it $[23,24]$. Mobile groups in this study had significantly higher likelihood of infection in men overall, but the risk difference was marginal in young men. However, we observed that even in these mobile groups there were significant prevalence declines in urban men and less prominent in the rural men. In younger people, we are persuaded to believe that if this bias was present, its effect was very minimal because the difference in odds of infection by mobility was non-significant and the major reason for absence was being away at school. Rather, it is likely that the prevalence among young people could even have been over-estimated due to the fact that those not found because of school attendance are less likely to be infected[25]. Notwithstanding the presence of selection biases due to non-response, they are unlikely to be an important factor explaining the sharp HIV prevalence declines among young people. We also note that where significant trends have been observed, all of the trends have been declining, irrespective of the factor being considered. This implies that there is no evidence of any interaction among the factors considered in this study.

External validity is a critical challenge when data from selected communities are extrapolated to the whole population. We found evidence supporting the interpretation that the HIV declines observed in these selected communities approximate well with those of the general population. Firstly, the prevalence levels of selected urban and rural communities matched with respective national estimates, and this was one of the criteria for selecting them[17]. Secondly, national ANC-based estimates show declines among young women[5]. Thirdly, we have previously reported that ANC-based trends under-estimate declines in the general population[10]. The main explanation for this reduced representativeness of ANC-based data was substantial delayed age at first birth among women in the general population.

HIV prevalence is a reflection of accumulations of infections over time, but during this same period, the population might change considerably[2]. Trend therefore reflects a time averaged dynamic balance between incidence, migration and mortality. The observed decline in prevalence could have been influenced by any or a combination of these factors. However, we realise that the changes were marked in young people where mortality is low and where there was no difference in odds of infection observed between in and out-migrants as observed elsewhere in the region[23]. Furthermore, the decline observed in higher educated young people who have adopted safer sexual practices is plausible because they have grown up during a time when prevention messages on HIV transmission were readily available, and this influenced their sexual behaviour[11]. In addition, we observe that if this trend continues, it has great potential to dictate further declines among educated people. HIV-related mortality's contribution to overall prevalence declines might reflect the impact of differential HIV-related mortality by age groups[2,26]. Long survival was unlikely to have any impact because access to anti-retroviral therapy was limited in this population before 2004 .

Men acquired infections later than females and reached peak levels after age 30 years, and even among men aged 50-59 years prevalence levels remained very high. In this region, a gender-generational-power imbalance exists between casual and regular sexual partners. Men are usually older than their female partners and this age difference has been found to be "the major behavioural determinant of the more rapid rise in HIV prevalence in young women than in men"[27]. Most of the infections in young women are from older men in whom there has been a power change through age rise related affluence $[27,28]$. In order to control the HIV epidemic, breaking this cycle should be the cardinal aim of prevention programmes.

There are still limited data from sub-Saharan Africa linking HIV prevalence to parallel changes in risk behaviours[29]. We collected behavioural data and HIV status concomitantly and work on detailed parallel sexual behaviour patterns and HIV trends are the focus of a separate paper (awaiting publication). We found reductions in high risk behaviours among young people and that these were particularly in higher educated and urban groups. These findings confirm the assumption that effects of educational attainment on risk of HIV infection is likely to be exerted through mediator factors such as more consistent condom use, lower likelihood of sexually 
transmitted infections and less number of sexual partners $[11,25,30]$.

\section{Conclusion}

We conclude that the observed changes among young people suggest that HIV prevalence is really declining in these communities. This is unlikely to be due to either measurement bias or the natural course of the HIV epidemic given low mortality rates in this group, rather might be linked with prevention efforts[7]. The prevention programmes initiated in Zambia, mainly since the early 1990s, were complex and used multiple approaches largely focussing on behaviour change, but were limited in parallel poverty reduction strategies. In these communities where HIV transmission is largely heterosexual, a logical explanation that we derive from the proximatedeterminant concept is that fear of HIV-related mortality combined with responses to prevention programmes may have influenced changes in behaviour thereby resulting in declines in HIV prevalence[30]. Key to this framework is the specification of a set of variables designated as "proximate determinants" (in this study it is condom use and number of partners) through which underlying factors operate to influence HIV prevalence. This interpretation is further supported by the fact that, over this period, transmission of HIV infection declined dramatically among higher educated people leading to a shift in the burden of infection from higher to lower educated groups. The changes observed among higher educated young people suggest that the availability of HIV preventive information was useful in forming their sexual behaviour, as they became sexually active after this critical information became well known[11]. An optimistic scenario is that these changes in higher educated groups will diffuse into those with lower education with time[31]. However, there is a negative association between educational attainment and poverty, manifested in this study by unchanging risk in lower educated and predominantly rural groups [32]. The link between HIV transmission and poverty might make such diffusion difficult. This suggests that prevention messages, though given, remain "irrelevant and inoperable" to many population groups whose poor economic and social conditions create an environment that might promote risky behaviours. Poverty reduction programmes, including strategies to increase educational attainment, are therefore to be seen as necessary components of effective HIV prevention efforts [32-34]. Furthermore, the observed prevalence decline is a sign that prevention works, and it should continue to be given "highest priority" among all other strategies including treatment efforts.

\section{Competing interests}

The author(s) declare that they have no competing interests in whatever form.

\section{Authors' contributions}

$\mathrm{CM}$ participated in the conception of the study, carried out the statistical analysis and drafted the manuscript. IFS reviewed all the drafts for intellectual content and participated in the interpretation of the findings. KD participated in the acquisition of data and review of the manuscript. SS participated in the critical review of the manuscript and was the lead person in the statistical handling and interpretation. KF conceived of the study, and participated in its design and co-ordination and helped to draft the manuscript. All authors read and approved the final manuscript.

\section{Acknowledgements}

The study was funded by the Norwegian Council for Higher Education's program for Development Research and Education (NUFU), Norwegian Ministry of Education, Research and Church Affairs through the Quota Programme and Norwegian Agency for Development Co-operation (NORAD). We also acknowledge the various contributions made by the following people for this study: The members of the Steering Committee for the project; Dr Francis Kasolo (who was in-charge of the laboratory services at the University Teaching Hospital); Ms Sheila Mwangala (University Teaching Hospital) who performed the laboratory tests; Research assistants and staff at the Kabwe General Hospital, University Teaching Hospital virology laboratory unit, Chelstone clinic as well as the National HIVIAIDS Council (NAC) and its forerunner, the Zambia National AIDS/ STD/TB \& Leprosy programme. Lastly but not the least we also thank the participants in the study.

\section{References}

I. Bello GA, Chipeta J, Aberle-Grasse J: Assessment of trends in biological and behavioural surveillance data: is there any evidence of declining HIV prevalence or incidence in Malawi? Sex Transm Infect 2006, 82 Suppl I:i9-il 3.

2. Gregson S, Garnett GP, Nyamukapa CA, Hallett TB, Lewis JJ, Mason PR, Chandiwana SK, Anderson RM: HIV decline associated with behavior change in eastern Zimbabwe. Science 2006, 3 I I:664-666.

3. Garcia-Calleja JM, Gouws E, Ghys PD: National population based HIV prevalence surveys in sub-Saharan Africa: results and implications for HIV and AIDS estimates. Sex Transm Infect 2006, 82 Suppl 3:iii64-70.

4. UNAIDS/WHO: "AIDS epidemic update: December 2005" special report on HIV prevention. Geneva, Joint United Nations Program on HIVIAIDS; 2005.

5. Sandøy Ingvild F, Michelo Charles, Kvåle Gunnar, Fylkesnes Knut: Antenatal clinic-based HIV prevalence in Zambia: Declining trends but sharp local contrasts in young women. Trop Med and Int Health 2006, I I:917.

6. Kwesigabo G, Killewo JZ, Urassa W, Mbena E, Mhalu F, Lugalla JL, Godoy C, Biberfeld G, Emmelin M, Wall S, Sandstrom A: Monitoring of HIV-I infection prevalence and trends in the general population using pregnant women as a sentinel population: 9 years experience from the Kagera region of Tanzania. J Acquir Immune Defic Syndr 2000, 23:4I0-4I7.

7. Ghys PD, Kufa E, George MV: Measuring trends in prevalence and incidence of HIV infection in countries with generalised epidemics. Sex Transm Infect 2006, 82 Suppl I:i52-i56.

8. Boisson E, Nicoll A, Zaba B, Rodrigues LC: Interpreting HIV seroprevalence data from pregnant women. J Acquir Immune Defic Syndr Hum Retrovirol 1996, 13:434-439.

9. Garcia-Calleja JM, Zaniewski E, Ghys PD, Stanecki K, Walker N: A global analysis of trends in the quality of HIV sero-surveillance. Sex Transm Infect 2004, 80 SuppI I:i25-30.

10. Fylkesnes K, Musonda RM, Sichone M, Ndhlovu Z, Tembo F, Monze M: Declining HIV prevalence and risk behaviours in Zambia: 
evidence from surveillance and population-based surveys. Aids 200I, 15:907-916.

II. Michelo C, Sandøy IF, Fylkesnes K: Marked HIV prevalence declines in higher educated young people: evidence from population-based surveys (1995-2003) in Zambia. Aids 2006, 20:1031-1038

12. Kwesigabo G, Killewo J, Urassa W, Lugalla J, Emmelin M, Mutembei A, Mhalu F, Biberfeld G, Wall S, Sandstrom A: HIV-I infection prevalence and incidence trends in areas of contrasting levels of infection in the Kagera region, Tanzania, 1987-2000. J Acquir Immune Defic Syndr 2005, 40:585-591.

13. Mahomva A, Greby S, Dube S, Mugurungi O, Hargrove J, Rosen D, Dehne KL, Gregson S, St Louis M, Hader S: HIV prevalence and trends from data in Zimbabwe, 1997-2004. Sex Transm Infect 2006, 82 Suppl I:i42-i47.

14. Boerma JT, Ghys PD, Walker N: Estimates of HIV-I prevalence from national population-based surveys as a new gold standard. Lancet 2003, 362:1929-1931.

15. Fylkesnes K Musonda, R. M., Kasumba, K., Ndhlovu, Z., Mluanda, F., Kaetano, L., Chipaila, C. C.: The HIV epidemic in Zambia: sociodemographic prevalence patterns and indications of trends among childbearing women. Aids 1997, I I:339-345.

16. Dzekedzeke K, Fylkesnes KM: Reducing uncertainties in global HIV prevalence estimates: the case of Zambia. BMC Public Health 2006, 6:83.

17. Fylkesnes K, Ndhlovu Z, Kasumba K, Mubanga Musonda R, Sichone $M$ : Studying dynamics of the HIV epidemic: population-based data compared with sentinel surveillance in Zambia. Aids 1998, I 2:1227-1234.

18. Glynn R Judith: Does increased general schooling protect against HIV infection? A study in four African cities. Tropical medicine \& international health 2004, 9:4-14.

19. Fylkesnes K, Kasumba K: The first Zambian population-based HIV survey: saliva-based testing is accurate and acceptable. Aids 1998, I2:540-54I.

20. Fylkesnes K, Siziya S: A randomized trial on acceptability of voluntary HIV counselling and testing. Trop Med Int Health 2004, 9:566-572.

21. Ghys PD, Walker N, Garnett GP: Improving analysis of the size and dynamics of AIDS epidemics. Sex Transm Infect 2006, 82 Suppl 3:iiil-2.

22. Hallett TB, Aberle-Grasse J, Bello G, Boulos LM, Cayemittes MP, Cheluget B, Chipeta J, Dorrington R, Dube S, Ekra AK, Garcia-Calleja JM, Garnett GP, Greby S, Gregson S, Grove JT, Hader S, Hanson J, Hladik W, Ismail S, Kassim S, Kirungi W, Kouassi L, Mahomva A, Marum L, Maurice C, Nolan M, Rehle T, Stover J, Walker N: Declines in HIV prevalence can be associated with changing sexual behaviour in Uganda, urban Kenya, Zimbabwe, and urban Haiti. Sex Transm Infect 2006, 82 Suppl I:i I-i8.

23. Mundandi C, Vissers D, Voeten H, Habbema D, Gregson S: No difference in HIV incidence and sexual behaviour between outmigrants and residents in rural Manicaland, Zimbabwe. Trop Med Int Health 2006, II:705-7II.

24. Sopheab H, Fylkesnes K, Vun MC, O'Farrell N: HIV-related risk behaviors in Cambodia and effects of mobility. J Acquir Immune Defic Syndr 2006, 41:8I-86.

25. Hargreaves JR, Glynn JR: Educational attainment and HIV-I infection in developing countries: a systematic review. Trop Med Int Health 2002, 7:489-498.

26. Blacker J: The impact of AIDS on adult mortality: evidence from national and regional statistics. Aids 2004, 18 Suppl 2:SI9-26.

27. Gregson S Nyamukapa, C. A.,Garnett, G. P.,Mason, P. R.,Zhuwau, T.,Carael, M.Chandiwana, S. K.Anderson, R. M.: Sexual mixing patterns and sex-differentials in teenage exposure to HIV infection in rural Zimbabwe. Lancet 2002, 359:1896-1903.

28. Glynn JR Carael, M.Auvert, B..Kahindo, M..Chege, J.Musonda, R., Kaona, F.,Buve, A.: Why do young women have a much higher prevalence of HIV than young men? A study in Kisumu, Kenya and Ndola, Zambia. Aids 200I, I 5 Suppl 4:S5I-60.

29. Garnett GP, Garcia-Calleja JM, Rehle T, Gregson S: Behavioural data as an adjunct to HIV surveillance data. Sex Transm Infect 2006, 82:i57-i62.

30. Boerma JT, Weir SS: Integrating demographic and epidemiological approaches to research on HIVIAIDS: the proximatedeterminants framework. J Infect Dis 2005, I9I SuppI I:S6I-7.
31. Rodgers EM: Diffusion of innovations. 4th edition. New York, Free Press; 1995.

32. Cohen Desmond: Poverty and HIVIAIDS in sub-Saharan Africa (issues paper no. 27). HIV and development programme [http:/l www.undp.org/hiv/publications/issues/english/issue27e.html].

33. Central Statistical Office (Zambia) CBHZ and ORC Macro: Zambia Demographic and Health Survey 200I-2002. Calverton, Maryland, USA, ORC Macro; 2003.

34. Central Statistical Office (CSO): Survey report prepared by the LCMS department. In Living Conditions and Monitoring Survey (LCMS) 2003-2004 Lusaka, Ministry of Finance and National Planning, (GRZ); 2004.

\section{Pre-publication history}

The pre-publication history for this paper can be accessed here:

http://www.biomedcentral.com/1471-2458/6/279/pre $\underline{\mathrm{pub}}$
Publish with Biomed Central and every scientist can read your work free of charge

"BioMed Central will be the most significant development for disseminating the results of biomedical research in our lifetime. "

Sir Paul Nurse, Cancer Research UK

Your research papers will be:

- available free of charge to the entire biomedical community

- peer reviewed and published immediately upon acceptance

- cited in PubMed and archived on PubMed Central

- yours - you keep the copyright 